\title{
WEAK CONVERGENCE THEOREM FOR PASSTY TYPE ASYMPTOTICALLY NONEXPANSIVE MAPPINGS
}

\author{
B. K. SHARMA, B. S. THAKUR, and Y. J. CHO
}

(Received 14 March 1996 and in revised form 18 August 1997)

\begin{abstract}
In this paper, we prove a convergence theorem for Passty type asymptotically nonexpansive mappings in a uniformly convex Banach space with Fréchet-differentiable norm.
\end{abstract}

Keywords and phrases. Iteration process, asymptotically nonexpansive mapping, uniformly convex Banach space, Fréchet-differentiable norm, fixed point.

1991 Mathematics Subject Classification. 47H09, 47H10.

1. Introduction. In 1972, Goebel and Kirk [3] introduced the class of asymptotically nonexpansive mappings and proved that every asymptotically nonexpansive self-mapping of a nonempty closed, bounded, and convex subset of a uniformly convex Banach space has a fixed point. After the existence theorem of Goebel and Kirk [3] several authors $([4,8])$ have shown interest in iterative construction of a fixed point of asymptotically nonexpansive mappings in uniformly convex Banach space. In these papers, Opial's condition [5] was a common tool for such construction.

Now, if we consider a space of type $L_{p}, p \neq 2$, then we find that Opial's condition fails to operate in it. Obviously, new techniques are needed for this more general case. These techniques were provided by Baillon [1] and simplified by Bruck [2], when the norm is Fréchet-differentiable, a property which is shared by both $l_{p}$ and $L_{p}$ spaces for $p \in(1,+\infty)$.

On the other hand, the concept of asymptotically nonexpansive mapping was further extended by Passty [6] to the sequence of mappings which are not necessarily the powers of a given mapping. He has shown that if $E$ has a Fréchet-differentiable norm and if $T_{n}$ is weakly continuous, then a fixed point of $T_{n}$ can be obtained by iterating $T_{n}$ starting at a point of asymptotic regularity.

In this paper, we prove that the sequence

$$
x_{n+1}=\alpha_{n} T_{n}\left(x_{n}\right)+\left(1-\alpha_{n}\right) x_{n}
$$

of Mann type iteration process converges weakly to some fixed point of $T_{n}$. Here $T_{n}$ is a Passty type asymptotically nonexpansive mapping defined in a uniformly convex Banach space equipped with Fréchet-differentiable norm. We emphasis that no asymptotic regularity condition is posed on $T_{n}$. Our result extends and generalizes the results of Passty [6], Xu [8], and others. 
2. Preliminaries. Before presenting our main results of this section, we need the following:

DEFINITION 1. A normed space $(E,\|\cdot\|)$ is said to be uniformly convex if for each $\epsilon>0$, there exists a $\delta>0$ such that if $x, y \in E$ with $\|x\|,\|y\|<1$ and $\|x-y\| \geq \epsilon$, it follows that $\|x+y\| \leq 2(1-\delta)$.

DEFINITION 2 ([6]). The sequence $\left\{T_{n}\right\}_{n=1}^{\infty}$ of self-mapping of a nonempty subset $K$ of a normed space $(E,\|\cdot\|)$ is said to be asymptotically nonexpansive if

$$
\left\|T_{n} x-T_{n} y\right\| \leq k_{n}\|x-y\|
$$

for all $x, y$ in $K$ with $\lim _{n \rightarrow \infty} k_{n}=1$, where $\left\{k_{n}\right\} \in[1,+\infty)^{N}$.

For abbreviation, we denote the set of fixed points of $T$ by $\operatorname{Fix}(T)$, the strong convergence by $\longrightarrow$, and the weak convergence by $\stackrel{w}{\longrightarrow}$, respectively.

We use the following lemmas to prove our main result.

LEMMA 1 ([7, Lem. 1.1]). Let $(E,\|\cdot\|)$ be a normed space. Let $K$ be a nonempty and bounded subset of $E,\left\{k_{n}\right\} \in[1,+\infty)^{N}$ with $\sum_{n=1}^{\infty}\left(k_{n}-1\right)<+\infty$ and $T_{n}: K \longrightarrow K$ be Lipschitzian with respect to $k_{n}$ for each $n \in N$. Then $\lim _{n \rightarrow \infty}\left\|x_{n}-x\right\|$ exists for each $x \in \bigcap_{n \in N} \operatorname{Fix}\left(T_{n}\right)$.

LEMMA $2([7$, Lem. 1.3]). Let $(E,\|\cdot\|)$ be a uniformly convex Banach space with Fréchet-differentiable norm. Let $K$ be a nonempty, bounded, closed and convex subset of $E,\left\{k_{n}\right\} \in[1,+\infty)^{N}$ with $\sum_{n=1}^{\infty}\left(k_{n}-1\right)<+\infty$ and $T_{n}: K \longrightarrow K$ be Lipschitzian with respect to $k_{n}$ for each $n \in N$. Suppose that $\left\{x_{n}\right\}$ is given by $x_{1} \in K$ and $x_{n+1}=T_{n} x_{n}$ for all $n \in N$. Then $\lim _{n \rightarrow \infty} J_{E}\left(y_{1}-y_{2}\right)\left(x_{n}\right)$ exists for all $y_{1}, y_{2} \in \bigcap_{n=N} \operatorname{Fix}\left(T_{n}\right)$, where $J_{E}: E \longrightarrow 2^{E^{*}}$ denotes the normalized duality mapping, i.e.,

$$
J_{E}(x):=\left\{u \in E^{*} \mid u(x)=\|u\|\|x\| \text { and }\|u\|=\|x\|\right\}
$$

for all $x \in E$ and, also, $\left(J_{E} u, u\right)=\|u\|^{2}=\left\|J_{E} u\right\|^{2}$ for all $u \in E$.

Now, we give our main result:

THEOREM 3. Let $(E,\|\cdot\|)$ be a uniformly convex Banach space with Fréchet-differentiable norm and $K$ be a nonempty, closed, and convex subset of $E$. Let $F$ be a subset of $K$ and $S=\left\{T_{n}\right\}_{n=1}^{\infty}$ be an asymptotically nonexpansive sequence of self-mappings of $K$ such that

$$
F \subset \bigcap_{n \in N} \operatorname{Fix}\left(T_{n}\right) \text { for a sequence }\left\{k_{n}\right\} \in[1,+\infty)^{N} \text { with } \sum_{n=1}^{\infty}\left(k_{n}-1\right)<+\infty .
$$

Suppose that $\left\{\alpha_{n}\right\} \in[0,1]$ and $\epsilon \leq \alpha_{n} \leq 1-\epsilon$ for all $n \in N$ and some $\epsilon>0$. Assume, also, that there exists a sequence $\left\{x_{n}\right\}$ in $K$ given by $x_{1} \in K$ and

$$
x_{n+1}=\alpha_{n} T_{n}\left(x_{n}\right)+\left(1-\alpha_{n}\right) x_{n}
$$

for all $n \in N$, for which

$$
x_{n_{i}} \stackrel{w}{\longrightarrow} z \text { implies } z \in F \text {. }
$$

Then either 
(i) $F=\varnothing$ and $\left\|x_{n}\right\| \longrightarrow+\infty$ or

(ii) $F \neq \varnothing$ and $x_{n} \stackrel{w}{\longrightarrow}$ an element of $F$.

Proof. Suppose that some subsequence $\left\{x_{n_{i}}\right\}$ of $\left\{x_{n}\right\}$ defined by (5) is bounded. Since $E$ is reflexive (every uniformly convex Banach space is reflexive), the subsequence $\left\{x_{n_{i}}\right\}$ must converge weakly to an element $z \in E$ and, hence, $z \in F$ by (6). Thus, $F=\varnothing$ implies $\left\|x_{n}\right\| \longrightarrow+\infty$.

On the other hand, if $F \neq \varnothing$, then there is some $y_{0} \in F$ and, by Lemma $1,\left\{\| x_{n}-\right.$ $\left.y_{0} \|\right\}$ is bounded, say, by $R$. Let $C=\left\{x \in K \mid\left\|x-y_{0}\right\| \leq R\right\}$. Then $C$ is closed, convex, bounded, and nonempty. Furthermore, $x_{n} \in C$ for all $n \in N$. In order to apply Lemma 2, we define

$$
U_{n}=\alpha_{n} T_{n}+\left(1-\alpha_{n}\right) I
$$

for all $n \in N$ where $I$ denotes the identity mapping. Then $U_{n}(C) \subset C$ for all $n \in N$ because $C$ is convex and $T_{n}(C) \subset C$. Additionally, we have

$$
\begin{aligned}
\left\|U_{n} x-U_{n} y\right\| & \leq \alpha_{n}\left\|T_{n} x-T_{n} y\right\|+\left(1-\alpha_{n}\right)\|x-y\| \\
& \leq\left[\alpha_{n} k_{n}+\left(1-\alpha_{n}\right)\right]\|x-y\| \\
& \leq k_{n}\|x-y\|
\end{aligned}
$$

for all $n \in N$ and $x, y \in C$. Furthermore,

$$
x_{n+1}=U_{n} x_{n}
$$

for all $n \in N$ and

$$
\bigcap_{n \in N} \operatorname{Fix}\left(T_{n}\right)=\bigcap_{n \in N} \operatorname{Fix}\left(U_{n}\right)
$$

because $\operatorname{Fix}\left(U_{n}\right)=\operatorname{Fix}\left(T_{n}\right)$ for all $n \in N$. Lemma 2 shows that

$$
\lim _{n \rightarrow \infty} J_{E}\left(y_{1}-y_{2}\right)\left(x_{n}\right)
$$

exists for all $y_{1}, y_{2} \in F$ and so, if $z_{1}$ and $z_{2}$ are two weak subsequential limits of $\left\{x_{n}\right\}$, then $J_{E}\left(y_{1}-y_{2}\right)\left(z_{1}-z_{2}\right)=0$. By (6), $z_{1}$ and $z_{2}$ are in $F$. Thus, we may take $y_{i}=z_{i}$ for $i=1,2$ and so

$$
0=J_{E}\left(z_{1}-z_{2}\right)\left(z_{1}-z_{2}\right)=\left\|z_{1}-z_{2}\right\|^{2}
$$

Since all weak subsequential limits of bounded sequence $\left\{x_{n}\right\}$ are, thus, equal, $\left\{x_{n}\right\}$ must converge weakly to an element of $F$. This completes the proof.

\section{REFERENCES}

[1] J. B. Baillon, Ph.D. thesis, Université de Paris.

[2] R. E. Bruck, A simple proof of the mean ergodic theorem for nonlinear contractions in Banach spaces, Israel J. Math. 32 (1979), no. 2-3, 107-116. MR 80j:47066. Zbl 423.47024 . 
[3] K. Goebel and W. A. Kirk, A fixed point theorem for asymptotically nonexpansive mappings, Proc. Amer. Math. Soc. 35 (1972), 171-174. MR 45 7552. Zbl 256.47045.

[4] J. Gornicki, Weak convergence theorems for asymptotically nonexpansive mappings in uniformly convex Banach spaces, Comment. Math. Univ. Carolin. 30 (1989), no. 2, 249252. MR 90g:47097. Zbl 686.47045.

[5] Z. Opial, Weak convergence of the sequence of successive approximations for nonexpansive mappings, Bull. Amer. Math. Soc. 73 (1967), 591-597. MR 35\#2183. Zbl 179.19902.

[6] G. B. Passty, Construction of fixed points for asymptotically nonexpansive mappings, Proc. Amer. Math. Soc. 84 (1982), no. 2, 212-216. MR 83a:47065. Zbl 489.47035.

[7] J. Schu, Weak convergence to fixed point of asymptotically nonexpansive mappings in uniformaly convex Banach spaces with a Fréchet-differentiable norm, RWTH Aachen, Preprint in Lehrstuhl C für mathematik no.21,1990.

[8] H. K. Xu, Existence and convergence for fixed points of mappings of asymptotically nonexpansive type, Nonlinear Anal. 16 (1991), no. 12, 1139-1146. MR 92h:47089. Zbl 747.47041.

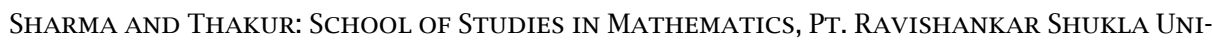
VERSITY, RAIPUR 492010, INDIA

Cho: Department of Mathematics, Gyeongsang National University, Chinju 660-701, KOREA 


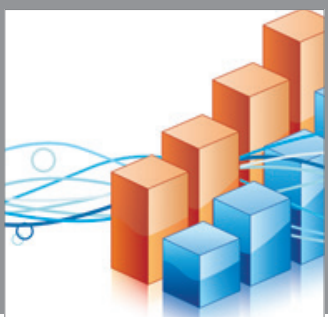

Advances in

Operations Research

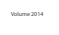

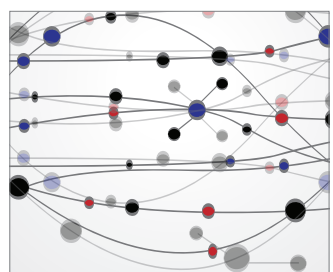

\section{The Scientific} World Journal
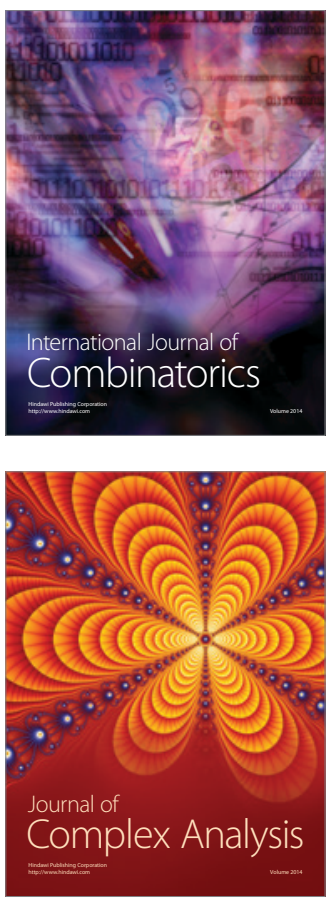

International Journal of

Mathematics and

Mathematical

Sciences
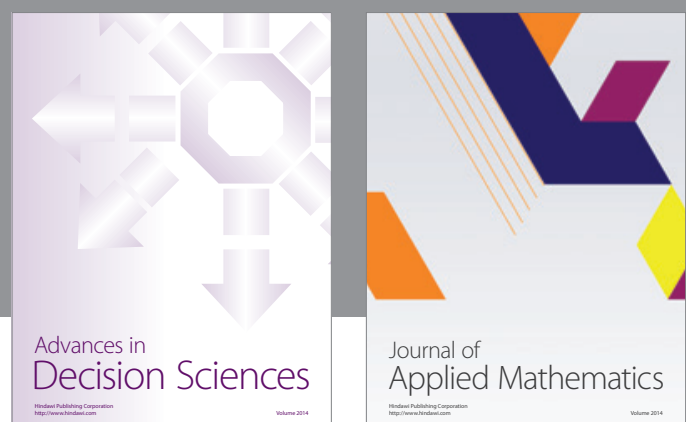

Journal of

Applied Mathematics
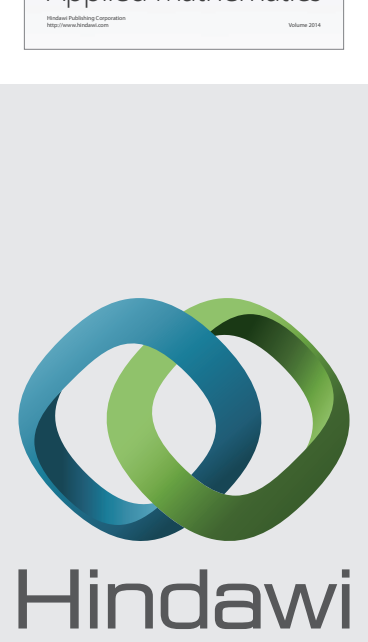

Submit your manuscripts at http://www.hindawi.com
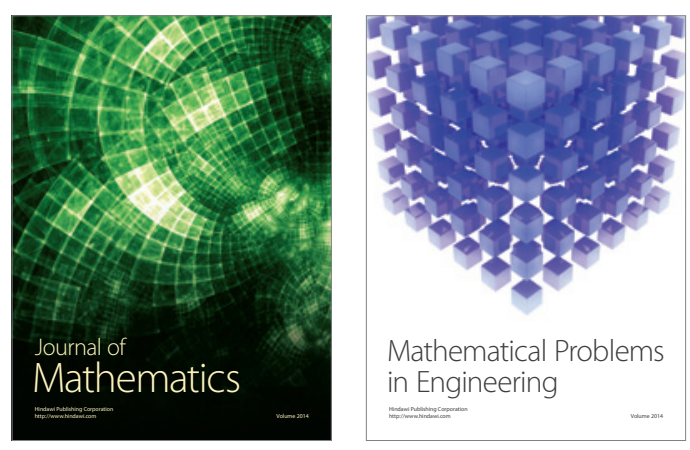

Mathematical Problems in Engineering
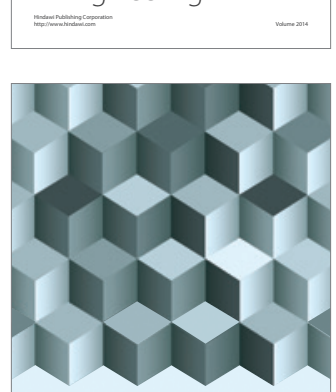

Journal of

Function Spaces
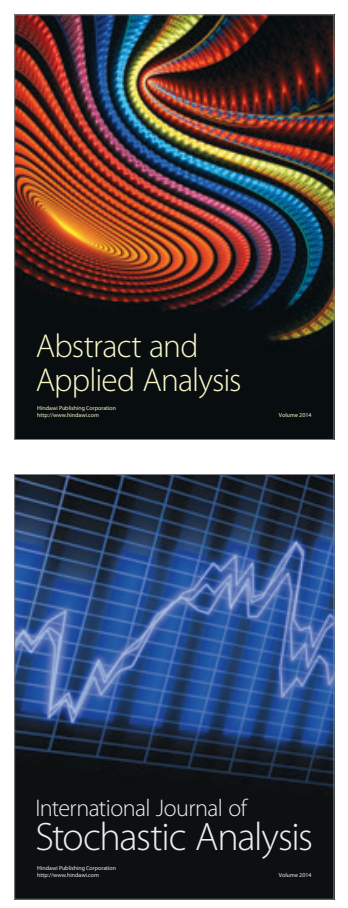

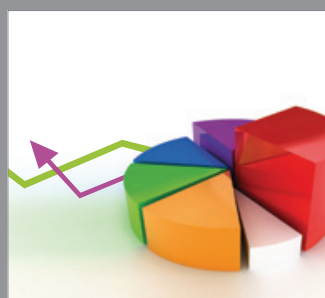

ournal of

Probability and Statistics

Promensencen
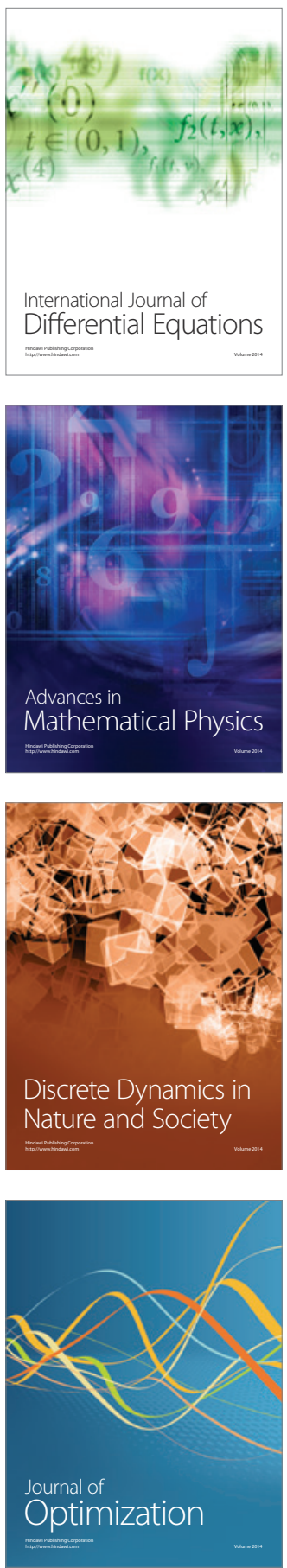